\title{
SIMULATION OF IMPORT TRANSACTION RISK ASSESSMENT UNDER ECONOMIC UNCERTAINTY
}

\author{
O. Martyanova ${ }^{1}$ \\ DOI: http://doi.org/10.15350/L_26/11/3
}

Abstract

The paper presents a methodical toolware for estimating the risk of import transactions and forecasting its level on the basis of the Markovian processes applied to develop optimal arrangements for risk management under economic uncertainty.

Keywords: analysis, currency risk, import transactions, foreign exchange rate, Markovian processes, methods, uncertainty, foreign currency liabilities, risk management, final probabilities, efficiency

When a brewer carries out import transactions, there is a risk associated with decision-making under economic uncertainty. Sources of uncertainty are instability of the political environment, the economic situation in the market, climatic and natural conditions, contractor's actions, inaccuracy of or no information about competitors' activities. Import transactions as an independent type of the international trade have a number of specific features affecting their purposes, objectives, conducting order and nature, that causes high risk exposure for importers, including a commercial risk, a currency risk, a transaction ineffectiveness risk and distortions in accounting (financial) records.

The term of import transaction risk is the complex multi-aspect category, which, in our opinion, explains the lack of a definition of this category in the scientific literature so far. We believe that the risk of import transactions cannot be considered solely from the point of loss as it contributes to income gain by an importer. Validity of this assertion is proved by the opinion of A. P. Algin identifying the risk with anticipated success, a favourable outcome [2, p. 7]. Considering the issue of defining this category V. V. Kovalyov describes a risk and income as two interrelated concepts because the assets associated with a relatively larger amount of potential losses are considered to be more risky. It is reasonable that such assets are subject to larger requirements for their profitability [5, p. 404]. Importance of risk and income interdependence when interpreting the category under study is specified by V. P. Kovalyov describing it as the action associated with hope for success [4, p. 80], by John F. Marshall and Vikul K. Bansal determining the risk through the possibility of income deviating from an expected or mean value [7, p. 177], F. Li Chang and Joseph I. Finnerti considering the risk in the form of probability of success or failure, where success denotes profit, and failure denotes loss [3, p. 142].

\footnotetext{
1Olga Martyanova, Candidate of Economic Sciences, doctoral candidate The Orel State University of Economics and Trade, Russia.
} 
The analysis of the mentioned definitions suggests the following wording of the import transaction risk which should be understood as probability of both favourable and unfavourable outcomes of a chosen alternative of their implementation under economic uncertainty.

Since the principles of scientific research are the source of development and improvement of the methodology, we can define basic conditions, provisions for arrangement of the analysis of import transaction risks that determine the perspective of their studying. The key principles of a risk analysis of import transactions are shown in Figure 1.

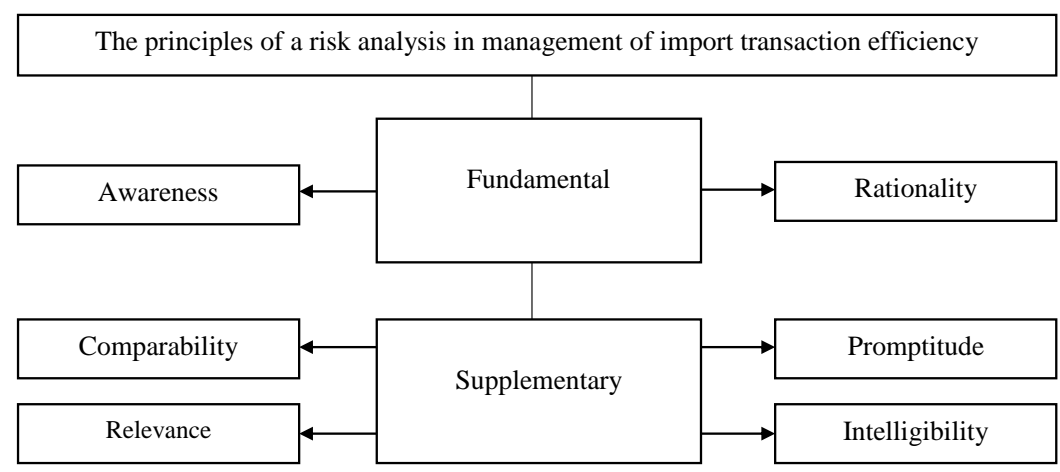

The source: prepared by the author

Figure 1. The principles of a risk analysis in management of import transaction efficiency

In our opinion, the fundamental principle is awareness of import transaction risk assumption, that is one of the conditions for managing efficiency of such import transactions since it is impossible to completely exclude the risk impact because of its objective nature.

Observation of the principle of rationality is based on the fact that costs related to risks levelling should not exceed an amount of loss that would be incurred by an importer in the case of adverse effects of a risk event.

We believe that evaluation of import transaction risks should be based not only on fundamental principles, including awareness of risk assumption and risk management expedience, but also on supplementary principles such as comparability of an accepted risk level with the expected income, information relevance as well as promptitude of their analysis and intelligibility of the results obtained.

The principle of comparability of the accepted risk with the expected income level and possibilities of an importer suggests that a company should accept only the level of the import transaction risk that does not exceed a forecast value of the transaction income. Taking excessive risks poses a threat to a company regarding retention of a capital share that provides internal insurance for that risk. Therefore, in order to avoid risks exceeding its capital, a business entity should simulate the effects of the risks. 
The principle of relevance defines risk information if it could influence economic decision-making. For this purpose, information should have the forecast or confirmatory nature. The principle of promptitude of a risk analysis manifests in the availability of information for making a decision on its basis when this information is able to influence such decision-making. The principle of intelligibility of risk evaluation results is ensured by the specificity of their classification, the choice of an assessment method, the clear presentation of information for quantifying a risk level of import transactions.

The process of a import transaction risk analysis should apply a multi-faceted approach to quantification of a risk level and selection of estimation methods. Measurement of a risk value depends on complexity and specificity of import transactions, completeness and reliability of an information base, personnel qualification, and possibility of using computer technologies. The risks that occur during import transactions can be classified and evaluated on the basis of the nature of their origin, thus allowing for establishing the maximum allowable risk limits for individual import transactions taking into account the current import strategy of a company. At the same time, a classification should be based on a detailed functional separation of import transactions within a particular business entity provided that it is aware of the fundamentals of the international trade, the economic analysis, and the industry features. The foregoing allows for the conclusion that each import transaction as a fact of the economic life of an importer should be considered from economic and legal sides. From the economic perspective, business operation are studied through techniques and methods of the economic analysis, and from the legal point of view, they are evaluated through available organizational documents for the right to perform this type of transactions provided by the obligations of import contracts, currency and civil statutory provisions.

The risk classification and analysis of import transactions are relied upon the mentioned point of view. The results of the studies performed allowed us to specify several classification features that identified the risks of import transactions carried out by brewing companies (Figure 2).

The risk classification according to the dependence rate on a business entity highlights external and internal risks due to both external and internal factors. The external risks are independent of the activities of a foreign economic market individual member as it is unable to influence such market. As opposed to the external ones, the internal risks are determined by the process of a company functioning in the area of foreign trade including the import sector.

When specifying a classification criterion by financial implications, one should distinguish between net risks and speculative risks. So, the net risks could be unambiguously described as getting a negative or zero result, for example, political, environmental, transport ones.

The speculative risks mean the possibility to get not only a negative result but also a positive outcome. Risk grouping according to the possibility of their forecasting provides an opportunity to present information on risks of import transactions in a general form. Thus, the predictable risks arise from the factors that could be simulated and their effects could be assessed. They are inflation, 
interest-rate risks. To analyze unpredictable risks we cannot form probabilistic models because they arise from the factors outside the control of an importer. This group includes, in our opinion, force majeure risks of import transactions.

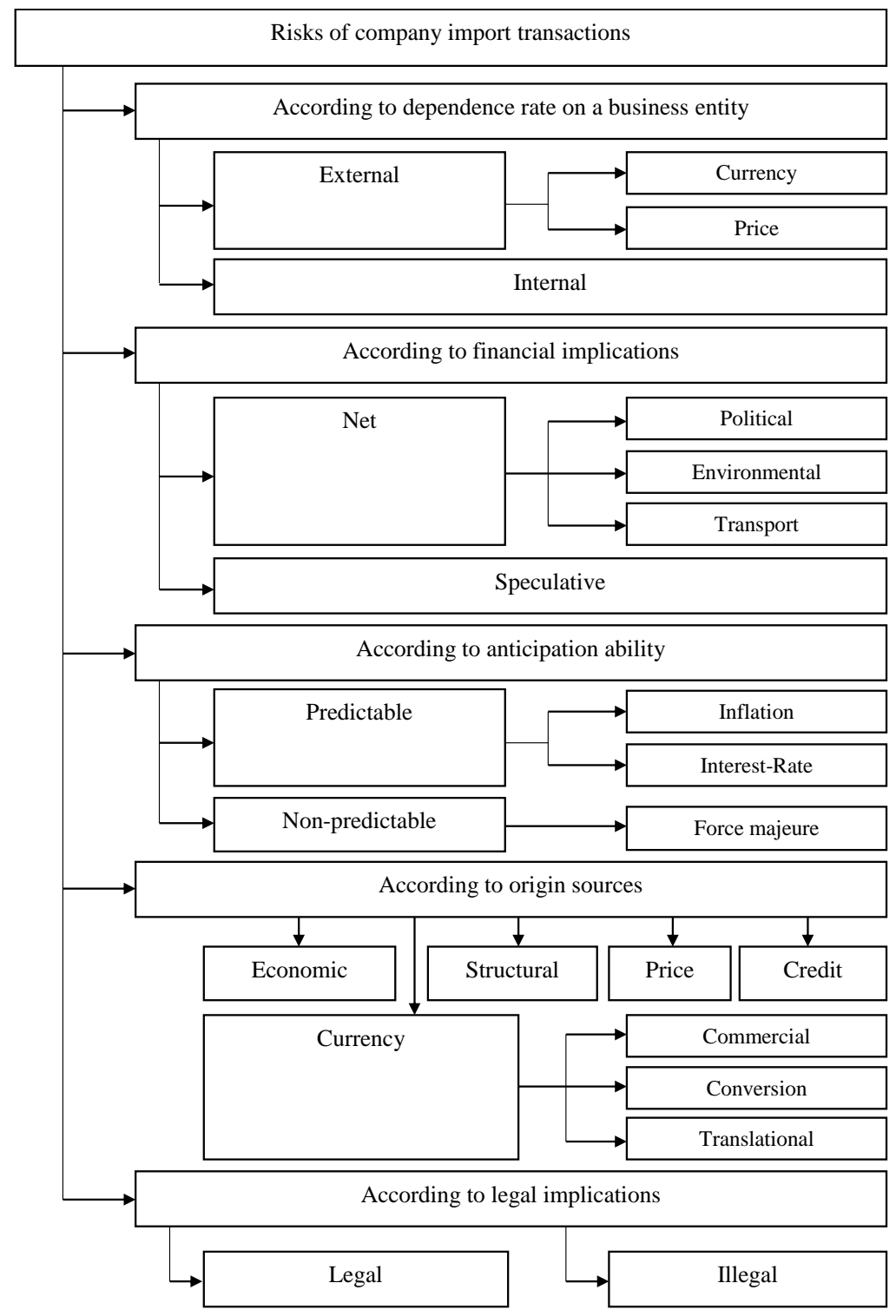

The source: prepared by the author

Figure 2. Risks of brewer import transactions 
The sources of the import transaction risks have an impact on the order in which they are analyzed. This classification criterion is the basis for the definition of economic, price, credit, currency and structural risks. So, the economic risks for a brewing company in its import transactions manifest in reduced volumes of foreign purchases of raw materials and, consequently, in the reduced production, the increased material intensity of a final product, slowing the capital turnover that contributes to a decline in efficiency of import transactions.

Among the risks classified by this criterion, there are also the price risks associated, on the one hand, with increasing prices of foreign suppliers for their products, an increase in tariffs on transport services for delivery to a buyer, and, on the other hand, with a worldwide trend of beer prices reducing.

The credit risk is related to the hazard of non-return money received by an importer from a bank on a repayment, maturity and serviceability basis due to the late payments by buyers for the products shipped.

The structural risks of import transactions are conditioned by changes in the ratio of permanent and variable costs and the debt ratio. A high percentage of permanent costs indicates a high level of operational leverage and, therefore, a high level of the risks associated with import transactions. Even a slight change in a volume of purchases from foreign suppliers as a result of the change in the beer output with a high operating leverage will significantly alter efficiency of an importer activity. A large proportion of debt is connected with significant costs for an importer. Therefore, if beer production and sales reduce, a company loses a large part of its income creating a risk of non-payment of credit interests.

The currency risks relate to foreign exchange rate changes. The exchange differences give an importer the possibility of getting loss of cash or income as a result of exchange rate fluctuations. In their turn, the currency risks may be divided into commercial risks that relate to the failure of a company to pay to contractors under its obligations; conversion risks, that is the risk of currency losses on specific import transactions, and translational risks arising from revaluation of the assets and liabilities of foreign affiliates, units of a business entity.

From the perspective of statutory regulation of import transactions, the risks can be classified as legal and illegal. The risks arising from the import transactions carried out according to the currency, civil and tax legislations should be considered legal, otherwise illegal.

The presented classification criteria are the most significant for the import transaction risk analysis since the risk groups identified in the classification have an impact on efficiency of import transactions and are the control points of the study. However, all the risks presented in grouping should be systematized in the relevant appendixes to management reporting as they are information media of a certain kind. In our opinion, the use of the selected classification criteria for the risk analysis contributes to disclosure of factors influencing a choice of a decision on management of import transaction efficiency. The proposed classification ensures more precise evaluation of risks for establishing the assessment toolware and forecasting their level in order to develop the best practices for risk management of import transactions. 
Corporate performance of an import company, in addition to the provisions of import contracts, is also influenced by changes of foreign exchange rates, which result in a significant increase in the currency risk that is explained by a number of circumstances. Firstly, an importer's debt in foreign currency leads to exchange rate differences, which could have both positive and negative effects for financial performance of a company carrying out import transactions. The same is the case for a business entity when it purchases foreign currency for payments within the current international trade as exchange rate fluctuations will also increase or decrease financial performance of a company. Secondly, advance payments in the fulfilment of import contract obligations deteriorate the currency and financial conditions of transactions for domestic importers. Thus, the higher a company's currency liabilities and the larger cash flows in the foreign currency are, the greater the currency risk of import transactions is, which makes it necessary to estimate a value of its impact on efficiency of a company's import activities.

The purpose and conditions of the analysis determine the choice of methods for quantification of risk levels for import transactions. The review of economic literature and other our studies revealed that a value of a currency risk is estimated using coefficients, the main ones being the ratio of foreign-exchange holdings and liabilities in the balance sheet currency, the net foreign exchange position, its share in equity capital, the ratio of currency costs in total expenses of a company, the ratio of exchange rate differences in profits prior to taxation. The analysis of these ratios describing potential loss of a company relating to its equity capital in the case of unfavourable changes in the rate, changes in costs due to exchange rate fluctuations, other expenditure patterns, the impact of exchange rate differences on financial results indicates that monetary foreign-exchange holdings and liabilities lead to the currency risks. Therefore, as recommendations for currency risk levelling, for example, in the case of foreign currency strength V. I. Barilenko proposes to a company to have a long currency position, and in the event of dropping a currency rate, the rational solution will be exceeding of currency liabilities over assets [1, p. 301]. However, the use of coefficients makes it possible, in our opinion, to analyze only economic effects of the currency risks for a company holding assets and liabilities with values in the foreign currency, to define performance of import transactions for the past reporting period, a month or a quarter, that is not interesting to a business entity making decisions to improve strategic management of import transaction efficiency.

We believe that import transactions based on a flexible, scalable model of a foreign trade strategy capable of meeting changing needs of a company in view of the dynamic geopolitical situation and economic instability will be effective. This requires the development of a toolware that helps a business entity build the import transaction processes on the basis of an analysis of foreign exchange rate changes, in order to reduce the impact of the currency risk and to increase their efficiency in the international trade. 
Making a management decision implies a comparative assessment of a number of alternative options and selecting the best one mostly complying to the management objectives $[9, \mathrm{p} .9]$. When developing a risk management system, the importers seek to build this process so that they can get information on the risks only in the form of specific numbers that reflect loss or income values. In our opinion, this is debatable because a risk is related to uncertainty, which can be taken into account in forecasting only using a probability model. To obtain specific results, it is appropriate to apply the Markovian processes for the risk analysis [6, p. 7].

For reasoning this assertion, we assess the currency risk arising from foreign exchange rate changes using probabilistic modelling. An importer when analyzing economic consequences of holding assets and liabilities in the foreign currency revealed the following trend: a rate growth may be replaced by a rate drop or remained unchanged for some time. A similar situation arises after reduction of its size. In addition, a period when the rate changes are so low that they can be neglected is also possible. The conditional probabilities indicating a respective state of the premium beer export market are specified in the transition probability matrix, $P_{c r}$ :

$$
P_{c r}=\left(\begin{array}{ccc}
0.4 & 0.5 & 0.1 \\
0.4 & 0.5 & 0.1 \\
0 & 0.2 & 0.8
\end{array}\right) \cdot(1)
$$

Upon receiving this information a company needs to assess a currency risk for the short-term prospects. We propose to solve this task using final probabilities as they do not only characterize the homogeneous Markovian process, but also reflect probabilities of the system states in the final steady mode where probabilities of the system states are independent of time and their initial distribution [6, p. 105].

Let us take a currency market where a company carries out its import transaction and purchases the foreign currency as the system $S$. The formatted graph of the system $S$ states is shown in Figure 3.

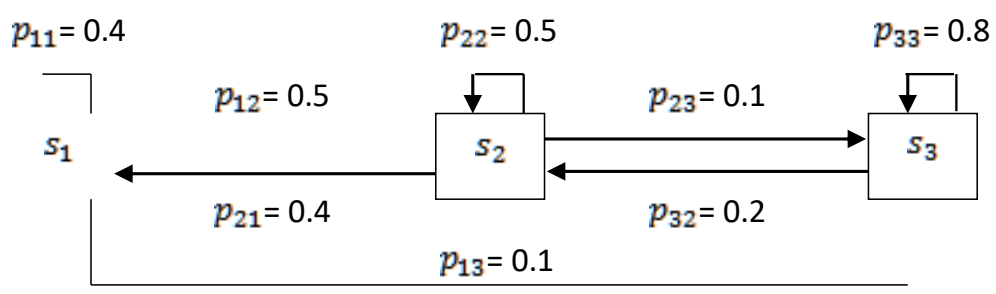

Figure 3. The formatted graph of the currency market states

As the system can be in one of three states according to the initial data:

$S_{1}$ - the foreign exchange rate growth;

$S_{2}$ - the foreign exchange rate is not changed;

$S_{3}$ - the foreign exchange rate drop; 
then the process that takes place in this system is classified as a discrete one. However, the time moments $t_{1}, t_{2}, t_{3}$ between the states are so small that the system $S$ does not change its state allowing the analyzed process to be interpreted as a discrete time process.

The state of the system $S$ in the future entirely depends on its current state regardless of its state in the past, therefore this process may be considered as Markovian [8, p. 123].

From the viewpoint of L. G. Labsker [6, p. 108], if a homogeneous Markovian process with the finite number of states is regular, then there are final probabilities $p_{1}, \ldots, p_{n}$. Such view is based on the fact that all elements of the matrix $P_{c r}$ are positive, hence the system $S$ is regular and therefore there are the probability limits $p_{1}, p_{2}, p_{3}$ of the states $s_{1}, s_{2}, s_{3}$, respectively.

In his paper L. G. Labsker [6, p. 106] justified that if there are final probabilities, then the final vector $\left(p_{1}, \ldots, p_{n}\right)$ could be found using the following equation

$$
\left(p_{1}, \ldots, p_{n}\right)=\left(p_{1}, \ldots, p_{n}\right) P,(2)
$$

where $P$ is the transition probability matrix.

Then, guided by this judgment, at $n=3$ from the equation (2) and using the matrix (1), we obtain

$$
\left(p_{1}, p_{2}, p_{3}\right)=\left(p_{1}, p_{2}, p_{3}\right) \times\left(\begin{array}{ccc}
0.4 & 0.5 & 0.1 \\
0.4 & 0.5 & 0.1 \\
0 & 0.2 & 0.8
\end{array}\right) .(3)
$$

When multiplying the row vector to the matrix in the right part of the equation, the expression (3) will take the following form

$\left(p_{1}, p_{2}, p_{3}\right)=\left(0.4 p_{1}+0.4 p_{2} ; \quad 0.5 p_{1}+0.5 p_{2}+0.2 p_{3} ; \quad 0.1 p_{1}+0.1 p_{2}+0.8 p_{3}\right)$.

Whence

$$
\left\{\begin{array}{l}
p_{1}=0.4 p_{1}+0.4 p_{2} \\
p_{2}=0.5 p_{1}+0.5 p_{2}+0.2 p_{3} \\
p_{3}=0.1 p_{1}+0.1 p_{2}+0.8 p_{3}
\end{array}\right.
$$

or

$$
\left\{\begin{array}{l}
0.6 p_{1}-0.4 p_{2}=0 \\
-0.5 p_{1}+0.5 p_{2}-0.2 p_{3}=0 \\
-0.1 p_{1}-0.1 p_{2}+0.2 p_{3}=0
\end{array}\right.
$$

Upon transformations we get

Whence

$$
\left\{\begin{aligned}
p_{1} & =0.667 p_{2} ; \\
0.5 p_{2} & =0.5 p_{1}+0.2 p_{3} \\
0.2 p_{3} & =0.1 p_{1}+0.1 p_{2}
\end{aligned}\right.
$$

$$
\left\{\begin{array}{l}
p_{1}=0.801 p_{3} \\
p_{2}=1.201 p_{3} \\
p_{3}=0.5 p_{1}+0.5 p_{2} .
\end{array}\right.
$$


The general solution of the equation (3) depending on one arbitrary parameter $p_{3}$ is the vector $\left(0.801 p_{3} ; 1.201 p_{3} ; p_{3}\right)$. By substituting the first equation in (4) by the normalizing condition, we get the system

$$
\left\{\begin{array}{l}
p_{1}=0.801 p_{3} ; \\
p_{2}=1.201 p_{3} ; \\
p_{1}+p_{2}+p_{3}=1,
\end{array}\right.
$$

upon solving that we can find the final probability vector of the system $S$ which looks like the following

$$
\left(p_{1}, \quad p_{2}, \quad p_{3}\right)=(0.267 ; \quad 0.4 ; \quad 0.333) .
$$

Due to calculations performed, it is possible to make a short-term forecast for the currency market that the exchange rate is probably $\left(p_{2}=0.4>p_{1}, p_{3}\right)$ to be unchanged or that it will fluctuate so little that the foreign exchange rate could be considered unchanged. The currency risks will therefore be minimized and independent of the initial state of the currency market.

The following conclusions can be drawn from the compilation of the analysis results.

Presenting the risk as a complex, multi-aspect category reflecting not only a hazard of loss but also likelihood of success, the paper argues the importance of risk study during the analysis of import transaction efficiency. When addressing the objectives of the study, the author proposed the definition of an import transaction risk based on the analysis of different information sources. We believe that the proposed definition meets the requirements of the effective legislation in both currency control and accounting.

The paper states that the risk analysis is the process that allows for identification, assessment, management and control of the risk level in order to improve import transaction efficiency. The identified distinctive features of the import transaction risk analysis allow us to formulate the principles that are typical for studying the revealed category. The study results prove that the import transaction risk analysis is based on both the fundamental and supplementary principles. The paper recommends the system of principles applicable to the import transaction risk analysis that will provide comprehensive assessment and systematization of such risks, help define the actions order in creation of the information base and develop a methodology for their analysis.

The paper reasons the conclusion that activities of companies carrying out import transactions involve the high currency risk. This conclusion is supported by the fact that, when analyzing performance of an importer's activity, it is necessary to assess how flexible a business entity could respond to negative foreign exchange rate changes. The obtained results show that the currency risk analysis and the identification of their trends require the development of an appropriate information base as the lack of data increases subjectivity of currency risk assessments and reduces efficiency of risk management.

The study proves that the important point in the currency risk management is prediction of its level and selection of its analysis method. This gives the grounds to offer the Markovian processes as the toolware for the currency risk analysis considering the selected classification criteria that permit to obtain accurate results under economic uncertainty. 
Based on the issues raised, the paper proposes the study of the currency risk taking into account the identified classification criteria, using the Markovian processes enabling a company to choose the best solution among the numerous alternatives available under economic uncertainty.

\section{References}

[1] Accounting, analysis and audit of the international trade: the education guidance/Under edition of professor V. I. Barilenko. - The second edition - M.: INFRA-M, 2012. 368 pp. - (Higher education).

[2] A. P. Algin Sides of economic risk [Text]/A. P. Algin. - M.: Knowledge, 1991 - 64 pp.

[3] Cheng, F. Li Finance of Corporation: theory, methods and practice [Text]: the textbook for Higher education institutions / Cheng, F. Li, I. Joseph Finnerti; the lane with English - M.: INFRA-M, 2000. - 685 pp.

[4] Kovalyov, V. P. Dictionary by the businessman of [Text] / V. P. Kovalyov. - Minsk, Higher school, 1995. - 320 pp.

[5] V. V. Kovalyov Introduction in financial management [Text] / V. V. Kovalyov. - M.: Finance and statistics, 1999. - $768 \mathrm{pp}$.

[6] L. G. Labsker Probabilistic modeling in financial and economic area [Text]: education guidance/L. G. Labsker. - The second edition - M.: INFRA-M, 2014. - 172 pp.

[7] John F. Marshall Financial engineering: a complete management on financial innovations [Text]/John F. Marshall, K. Vikul Bansal; the lane with English; edition G. Agasandyan. - M.: INFRA-M, 1998. - 783 pp.

[8] 0. V. Martyanova Model of the impact assessment price risks in the conditions uncertainty on efficiency of the foreign trade business activities with use of hedging and markov processes [Text]/O. V. Martyanova // Audit and financial analysis. - 2016. No. 4. - Page 113-126.

[9] Vasilchuk, O. I. Use of the management decisions [Text] this managerial accounting in case of acceptance / O. I. Vasilchuk // Karelian scientific magazine. - 2013. - No. 2. Page 8-10. 